\title{
THE TEACHING OF HISTORICAL GEOLOGY AS A FACTOR CONDITIONING RESEARCH ${ }^{1}$
}

BY JOHN C. MERRIAM

(Presented before the Society December 31, 1919)

CONTENTS

Function of the educational institution in development of research..... 339

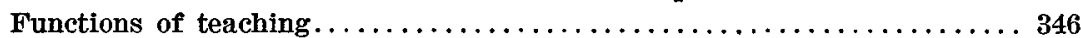
Special significance of geology in teaching idea of continuity in research. . 348

\section{Function of the mducational Institution in Development OF RESEARCH}

Discussion of the teaching of any research subject involves preliminary consideration of the position of the educational institution in relation to that of other agencies concerned with the advancement of research. Viewed from the standpoint of one surveying the work of investigation as now expressed in this country, we may divide our greater research agencies tentatively into five groups.

Without assuming to present a complete or exact classification, these are: (1) research of practical application in engineering laboratories; (2) governmental bureaus and laboratories; (3) research foundations; (4) museums and allied institutions; (5) educational institutions. To these five a complete statement would add several of lesser magnitude, among which a very potent force is found in effort of individuals working privately, as has been done to the great advantage of science by many pioneers in investigation.

In order to make clear the position of educational institutions with relation to the other four kinds of research agencies, it is necessary to give an approximate definition of each type.

\footnotetext{
1 Manuseript recelved by the Secretary of the Soclety August 12, 1920.

This paper is one of a series composing a symposium on the teaching of geology and paleontology.
} 
(1) The expression of research referred to as "practical application in engineering laboratories" includes use of science in development of economic interests in the great variety of ways in which investigation contributes to the good of mankind. The words "engineer" and "science" are here. used in the widest sense, covering the appliers of knowledge secured by investigation. The operations of this group might be illustrated by the constructor of railways, the builder of aeroplanes, or the dentist. The work of the engineer in all of the fields in which he operates may, unfortunately, be carried on by rule-of-thumb application without consideration of the special merits of each case. The true engineer we all recognize as one who views each problem as a new subject for special study. In a large measure, his judgment must be based upon previous experience with similar studies, but his greatest success comes through realization of the fact that each bridge to be built, whether it be intended to cross a river or only to reach from one tooth to another, presents a special problem not identical with any previously considered case, and that failure to see the individual peculiarities may mean inability to make full use of the principles which are his instruments. The successful engineer is continuously engaged in the application of research methods.

In a still larger sense does the engineer concern himself with research problems by consideration of questions which are not merely specific applications, but involve principles which must be better understood before he is able to proceed. The dentist recognizes that knowledge of microscopic structure of the tooth is of fundamental importance in his treatment of tissues, if this work is to have value in a degree of permanence measured in years or tens of years. The railroad builder realizes that not all rock foundations give real stability to a railway bed, and that an understanding of the material through which he cuts may determine the ultimate value of his constructive work. These investigations in engineering inquiry we often designate as research in applied science. They differ from those in so-called pure science only in the fact that the research of the engineer is specifically directed, and by nature of the inquiry is rather narrowly limited, whereas the real solution of the problem may lie in a rather remote field. The railway builder may find the answer to his engineering questions in special phases of chemistry or petrography which were not included in the curriculum of his training course.

Even with the limitations which are set in investigations designed to meet specific needs in restricted fields of applied science, we must recog- 
nize that the every-day operations of great laboratories conducted by farseeing corporations are developing some of the most significant advances in fundamental science of today. The student of pure science must always keep in close contact with these special researches, both to be helpful and to receive from the engineer the great wealth of data which should be incorporated into the organized body of fundamental science.

(2) Government institutions, as exemplified by the federal bureaus and laboratories of the United States, represent a field which is in some respects intermediate between that of engineers who apply and that of the special students of pure science concerned only with the principles of their subjects. The laboratories of government departments exist for the special purpose of contributing for the benefit of the community. It is necessary that they serve as sources of information for practical applications and for interpretation of the principles of science to the great group of inquiring engineers throughout the country.

Consideration of scientific problems relating to specific community needs leads the government bureau to undertake far-reaching and fundamental investigations in the broadest fields of applied science. Such researches, by reason of the wide range of interests covered, may extend farther than the studies of the engineer or the corporation. As institutions which stand for a continuing people, the government bureaus should be able to undertake inquiries from which results might first become available to later generations. It is unfortunate that budget requirements and responsibilities of political parties tend to limit us in handling of projects which should be continued for long periods or with large funds, for the expenditure of which immediate returns may not be visible. It is presumably true that all science has its application in one form or another, but exceptional vision is required in organization of government work to make it clear that every phase of each investigation undertaken represents efficient application of science for real needs. By reason of its practical limitations, the government organization may lose opportunity for consideration of certain critical problems the settlement of which would ultimately be of great advantage to the state.

(3) Research foundations, with ample resources, freedom of choice in selection of objectives, and with trained men of vision directing their researches, have given opportunity not otherwise available for exhaustive investigation of fundamental problems and groups of problems without regard to the time required in the study and without reference to immediacy of pressure for application. These institutions have in some measure covered the fields for basic investigation which the corporation engi- 
neer and the government bureau could not readily reach. The efficiency attained by these foundations, the vision with which their problems have been selected, and the great contributions which they have made to science, to human thought, and to application of science in every-day life rank among the greatest achievements of American science.

(4) The great museums of America have been strongholds of research in the natural sciences. Their function has generally involved the special study of wide or narrow geographic regions to which they are related through circumstances governing their origin. The museums have also served a most important purpose as educators in natural history, supplementing in a vital way the work of the schools and universities. Through interpretation of science to the great public, the museums have greatly assisted in the effort to make knowledge and reason the basis of our community judgment and to give research the fullest opportunity to serve the people.

In organization of purely research projects the museums have contributed a large share of the material upon which the advance of American natural history has been based.

The work of these institutions is in general characterized by peculiarly close relation to public welfare, both in effective educational work and in the support of fundamental investigations for the sake of their human interest. The museums fill a most important place in the scheme of our research development.

(5) The educational institutions of America, as represented by the universities and colleges, have always had a large place in the advance of knowledge in all its phases and in its application. Their range of operation in constructive scholarship has been as wide as the limits of learning and its use.

In schools of engineering and agriculture, research has been largely on specific problems of application not differing from those of the engineer's laboratory or the government bureau. Here, as in the departments of fundamental science, the researches have also ranged into all phases of description, organization, interpretation, and analysis in special phases of science for which no immediate application is considered. These activities have been financed in some part by the universities and in part from the pockets of the professors. Considerable support has also come from business interests, from government institutions, and from research foundations.

The university or college includes constructive work as a necessary part of its regular program for at least four reasons, which may be stated as follows: 
(a) Investigation is an indispensable means of keeping the faculty in a position to present the most fundamental and most advanced knowledge through its teaching.

(b) Training in creative or constructive work is one of the most important phases of teaching and can be carried out successfully only through actual experience of the student.

(c) The state will naturally depend upon the institution of higher learning as an exceptionally organized group of constructive experts prepared to consider urgent questions requiring investigation.

(d) As a body representing a wide range of closely interlocking subjects having continuous relation to research in one form or another, the university affords unusual opportunity for correlation of knowledge on questions in new fields of thought.

In considering the first reason (a) we must realize that, even if the universities be assumed to exist only for teaching, they are expected to present the most advanced thought, and we can not keep them in a position of leadership in understanding and in training without a faculty continuously setting forth the best in thought and experience in every subject. This condition can be maintained either by continuous research on the part of the faculty or by continuous renewing of the membership of the faculty. Continuous replacement of individuals is impossible, as the institution is a great and complex instrument in which the parts can be kept in proper adjustment only through long contact. It therefore becomes necessary for the faculty to keep its position by continuous growth of its members. If this process is merely imitative, the teacher is not an authority. The only way in which he can be assured of growth is by working in his specialty. This constructive operation involves intimate knowledge of the fundamentals of his subject and definition of the limits and relationships of his chosen field of study.

More than this, the function of teaching in an educational institution does not concern alone the retailing of facts already assembled; it must include that kind of understanding of the subject which will prepare the student for his task as a leader in the future. To become such a leader the student must look beyond our present knowledge and experience with the expectation of accomplishing things which have never before been done. No good instructor can avoid recognizing this need of his students. No teacher who sees this requirement can fail to make a serious effort to determine the direction of advance in constructive use of his subject, if for nothing more than to point out to students the trend of the path and the preparation necessary for those by whom it will be extended to new fields of usefulness. It is hardly possible for the instructor to obtain a 
clear view of future development in his subject without intimate personal relation to the most advanced work in progress.

From the point of view of the student, training in constructive work or in development of creative imagination, suggested in point (b), must be considered of importance at least equal to the securing of information or the disciplining of the mind to habits of work. As in no other type of mental attitude, this involves the acquiring of a distinct love of the work and understanding of its purpose. It is not conceivable that the university will neglect this extraordinarily important aspect of the student's preparation for future activity, or that it will expect the student to proceed. without guidance. If this particular phase of educational activity is not to be eliminated, it places upon the instructor the requirement that he stand before his students as an unmistakable representative of creative work and as illustrating in his personal attainment the end or purpose of his effort. Evidence of any other attitude on the part of the instructor will make useless whatever attempt he may make to serve as a leader or adviser in the field of constructive study.

The third contribution of value $(c)$ furnished by research related to education concerns the immediate use of the results of this study by the community. While the university is naturally assumed to be primarily an educational institution, it has been made clear that without continuing research it can neither provide adequate instruction nor maintain its leadership in the educational work required. Constructive problems in all departments of investigation must be continuously the subject of successful handling, and the results of this work will be products of the first importance to the community. It is natural that to such an institution the whole people will look for the appearance of new ideas of broadest significance and of practical value. It is to be expected that the state will depend upon the university for information and will expect it to furnish the necessary knowledge and the constructive ability required in meeting new situations that make necessary the building of new plans of thought for community use. The contributions made by research in these institutions will generally tend to concern fundamental subjects and to group themselves on the more indefinite areas along the borders of knowledge, but it is frequently these broader principles which offer the largest opportunity for real addition to the sum of immediately useful information.

The fourth reason $(d)$ for including research as a part of the necessary program of an institution of higher learning involves one of the distinguishing characteristics of the university. By reason of the extraordinary scope of interests represented in such a body, one might expect the 
unusual opportunity for contacts of investigators in related fields to produce new combinations of formula, and through these the opening of new fields of discovery. No other organization presents the same wide range of subjects represented by leaders of thought who are normally investigators. To these conditions the university adds an unusual freedom of opportunity for choice of materials or combination of materials to be used in investigations, as also the stimulating influence of a continuous stream of students with new inquiries and new ideas. In no other type of institution engaged in investigation are the chances greater for contribution in fields representing either new groupings of subjects or areas which have thus far remained untouched by the workers of all organized departments of knowledge.

For all of the reasons that have been presented, research has now an established place in institutions for higher learning. The position of constructive work in the universities is clearly not accidental, but relates to the generic characters of these institutions.

To the university, viewed as the highest training school, investigation becomes as necessary for natural activity as eating and assimilating are to continued effectiveness of the biological organism. The research so necessary to continuance of adequate instruction we come to recognize as a normal part of the life of the institution, and we look to this kind of an organization in the course of its growth to produce much of value in the forefront of discovery and construction.

The university fails of its mission in creative work in many instances because, of all the types of institutions, it is the most imperfectly financed for this phase of the work which it should naturally conduct. With the clear requirement that, to keep its position in the first line of advanced thought, it must consist of men of the best type in the professions, the university is often financed almost exclusively for teaching and administration without reference to research, and it is assumed that the constructive work so necessary to development of the faculty and students will be cared for in other ways. Beyond funds for purchase of books, departments with large salary rolls for instruction often show almost nothing for constructive work. The ultimate result of this policy must be failure to attain the full measure of efficiency. Under unfavorable conditions potential leaders in the faculty will either find support of their greatest contributions to knowledge outside the institution or, failing in this, they will burn out like a lamp producing feeble light by consuming a wick to which no oil is fed.

The university and college, then, take their places with, other groups of research agencies of the country as institutions caring for the initial 
training of nearly all investigators, and particularly given to wide range of researches among a great variety of fundamental subjects. Their activities in constructive work will often run parallel with those of other kinds of organizations; but breadth of interest, wide range of contact, unusual freedom of relationship, and spontaneity will always be among their characteristics.

\section{FunCtions of TEACHING}

Having defined in some measure the position of the educational institution with reference to research, one naturally inquires further concerning the more intimate relation of the methods of teaching to research in the institution. This discussion may be introduced by a brief analysis of the function of instruction as we may interpret it for the institution of higher learning.

The principal objects of teaching in a university or college, as understood by many of us, may be considered as of four kinds: (1) informational, (2) organization and presenting of perspective, (3) stimulative, (4) constructive.

(1) Informational teaching is a descriptive process concerning the transmission of facts which may or may not be available elsewhere. There are many cases in which the inadequacy of existing information and the position of the instructor as an expert justify the presentation of data which may not be obtained otherwise. The reiteration of statements already set down in text-books or in other literature easily available may in many cases be of importance because of the touch of personal relation in the presentation. On the other hand, a large part of the information transmitted in purely informational courses may be dangerous to the student, as it inhibits personal effort to go to the available sources for knowledge; and dangerous to the instructor, because it takes his time from other kinds of instruction which may be more valuable.

(2) Organizational instruction begins with masses of fact available and teaches their grouping and use as more or less complicated organized bodies. It represents in some respects a higher use of knowledge and involves a more difficult kind of presentation.

One of the important phases of instruction consists in that type of organization which permits one to see knowledge in the simplest form of statement, and at the same time to realize the infinity of detail and the position of details with reference to the larger principles involved. Not too many individuals recognize the importance of organization of information and the impossibility of effective use of knowledge without understanding the interrelation of its elements. Not a few individuals 
accumulate vast bodies of detailed information without being able ever to arrange them in such a way as to serve as other than an impediment to advance by reason of clogging of the machinery through the pressure of disorganized and unrelated materials. Others see each subject in its simplest form, and may serre as guides to indicate the direction in which larger movements will go, but are limited in the use of their judgment by reason of lack of relation between general principles and the details through which the principles must in their application be ultimately expressed. One fundamental principle of university instruction involves the larger organization which makes possible a view showing us knowledge perfect in the simplicity of the interlocking parts and infinite as to the details of expression.

(3) The second view of university instruction, which we have just discussed, gives the factors of discipline and order as the most fundamental and significant. Contrasted with this idea, we have the considerations of interest and pleasure in the inquiry into a given subject developed through stimulation in the statement of the instructor. While it may be true that many students are not worth while, by reason of their constitutional limitations in relation to the subject which they approach or with reference to the particular instructor with whom they come in contact, there can be no doubt that a great number of students also fail because of not having set before them, through the stimulation of clear presentation, the really fundamental ideas basic to subjects in which they might naturally be interested.

(4) Developing the power to do constructive or creative work constitutes the highest object of the student. The ability of the instructor to bring out this quality of mind is the greatest gift. The desire to construct generally arrives most readily through participation in constructive work, and involves the idea of research as a normal part of the program of the university. This view can be presented or suggested-in realistic manner only by those who are engaged in actual research. In other words, the institution which fails to give proper opportunity to develop its faculty in constructive work fails to secure the results of highest type in its teaching.

In the statements that have been presented up to the present stage of this paper it has been my purpose to make clear that teaching, as expressed in colleges and universities, serves its highest purpose as training when it develops in the student the ability to see with a true perspective, and to use his subject as a means for constructive effort. At the same time it has become evident that the educational institution is not only the most important molding influence for all future investigators, but 
that it is itself one of the greatest types of creative institutions, occupying a position distinguished by breadth of interest and by opportunity for contribution to the basic elements of science. Considering its largest usefulness, there is every reason for holding that, whatever else may be included in a university program, the interests of the teacher, the taught, and the community demand that a knowledge of needs and objects for future constructive work and an understanding of the mode of operation of the creative mind shall always be dominant features.

\section{Special Significance of Geology in Teaching Idea of Contindity IN RESEARCH}

What has been stated regarding the problem of the educational institution as a whole applies without amendment to the fields of instruction in geology in all of its phases. I have presented the problem in this general form in order that in further discussion we may more readily express the relation of the teaching of geology to that in other subjects. $\mathrm{My}$ desire is to emphasize the point that teaching conducted in such a way as to fail of stress on the constructive element expresses a condition less advanced than that of full leadership and promises for the future a result corresponding to what has been accomplished rather than what should be done. Geologists have always been a constructive group of scientists, and we may trust that in the further progress of educational work in this field the example of research activities of our distinguished predecessors may serve to establish the method for future advances.

In addition to consideration of the relation of teaching to research expressed in geology, along with all other phases of scientific inquiry, I wish to direct attention to a peculiar relation between the historical phase of geology and other aspects of this science, as also the relation of this aspect of geology to other sciences. It is stated only briefly as indicating an influence of the teaching of this subject upon the general development of research.

Great advances in knowledge are not infrequently made by sudden flashing up of genius opening the way into a new field. Some hold that these individual efforts, unrelated to other researches, represent the normal method of advance of science. Important as these individual contributions may be, careful study indicates that a very large part of the general forward movement is made possible by the fitting of moderate individual contributions into a larger scheme in which the relations of all the parts are known. Through an understanding of the continuity or interrelationship of the facts in the whole field of knowledge it be- 
comes possible to obtain the widest meaning and largest value of each fact. The mind that sees these interrelationships-perhaps through the occasion of having brought a new element into the scheme-is the one that makes the greatest and most useful contributions. This idea of continuity is one which needs large cultivation in science. We may approach it from various directions. One of the most important and most effective means of coming to recognize it is by the historical view. History, interpreted in the truest sense, gives a feeling of broad connections in time and space and origin not excelled in any other field and equaled in few. I am convinced that the wider outlook given by this kind of contemplation is one of the most desirable fundamental elements in the education of a becoming investigator in any subject. We find historical geology giving the grandest of all strictly historical or continuity views. I am confident that the proper expression of this subject in the education program would exert an influence of wide extent contributing to development of a better understanding of the idea of continuity in science and greatly advancing the interests of research in all fields. I believe that a certain responsibility rests upon the geologist to see that this wider view is sought with increasing interest, and I feel assured that we have large

- opportunity to exert an influence upon the development of connected constructive thought in the whole education scheme of the great institutions of learning. 
